\title{
A Comparative Study of Endoscopicseptoplasty With conventialseptoplasty
}

\author{
Dr.Dharmendra Kumar ${ }^{1}$, Dr. Varunkumarthakur ${ }^{2}$, Dr.S.P Singh ${ }^{3}$ \\ ${ }^{1}$ Senior Resident DeptOf Otorhinolaryngology J..L.N.M.C.H Bhagalpur,Bihar \\ ${ }^{2}$ Associate Professordept Of Otorhinolaryngology J..L.N.M.C.H Bhagalpur,Bihar \\ ${ }^{3}$ Assistant Professordept Of Otorhinolaryngology J..L.N.M.C.H Bhagalpur,Bihar
}

\begin{abstract}
The study was carried out to compare the postoperative morbidity among patients of conventional andendoscopicseptoplasty and to assess the efficacy and use of endoscopic septoplasty with other endoscopic surgeries.BetweenNov 2015 and Nov 2016, 50 patients underwent septoplastyplasty, 25 were endoscope assisted and 25 were convential.The difference in the functional outcome of both the surgeries was insignificant. There was a significant difference with respect to complication.Posterior deviations were best corrected by endoscopic septoplasty. Complication rate washigher in conventional septoplasty. The endoscopic approach to septoplasty facilitates accurate identification of thepathology. It facilitates realignment by limited and precise resection of the pathological areas .Complications are lesser with endoscopic septoplasty.
\end{abstract}

Keyword:Septoplasty, Endoscopic septoplasty, Conventional septoplasty

\section{Introduction}

Nasal obstruction is one of the most common complaint that aotorhinolaryngologist faces in the day to day practice. Deviated nasal septum is one of the most common cause for the nasal obstruction. Apart from nasal obstruction a a significantly deviated nasal septum hasbeen implicated in epistaxis, sinusitis, obstructive sleepapnea and headaches attributable to contact points withstructures of the lateral nasal wall .Surgery on DNS changed a lot, starting from radical septal resection to mucosal preresevation and subsequent preservation of possible septal frame work. With the introduction of endoscope into the field of otolaryngology, there were efforts to use it for the correction of deviated nasal septum targeting the surgical procedure in removing only the deviated portion, spur and maxillary crest. It is more effective with minimal manipulation. And also had the advantage of diagnosing and treating the abnormalities of the lateral wall of the nose at the same sitting.This study was taken up to compare the two techniques i.e., conventional and endoscopic septoplasty.Preoperative symptom analysis technique of surgeries postoperative analysis and complication presented in this study have been evaluated.

\section{Material \& method}

50 patients of deviated nasal septum were selected by simple random sampling method, who were admitted in the department of Otorhinolaryngology, of J.L.N Medical College and Hospital, Bhagalpur , from Nov 2015 to Nov 2016. They were divided in to group A and B, with 25 cases in each group.Group A underwent conventional septoplasty and group B underwent endoscopic septoplasty.

\section{Inclusion criteria}

Patients with nasal obstruction,nasal discharge, hyposmia, post nasal drip, facial pain and headache were included in the present study

\section{Exclusion Criteria}

Patients with allergic rhinitis andupper respiratory tract infection were excluded.

\section{Methods of Collection of Data}

Cases selected for the study were subjected to detailed history and clinical examination. They were evaluated subjectively and objectively before the surgery. Nasal patency test was done followed by anterior rhinoscopy and using Gertner-Podoshin plate. Deviation were classified as right or left or S shaped depending on the side of deviation. Depending on the involvement of cartilaginous or bony parts of septum they were classified into anterior or posterior or both. Posterior rhinoscopy was done in all patients to rule out other pathologies. Diagnostic nasal endoscopy was performed. CT scan of nose and paranasal sinuses were done in selected cases. A correlation was established between clinical features and endoscopic findings. After complete pre operative evaluation patients were subjected to surgical intervention. Standard techniques of conventional and endoscopic septoplasty were followed. 


\section{Technique For Endoscopic Septoplasty:}

The procedure was performed under local or general anaesthesia. The septum was injected with $1 \%$ xylocaine in 1: 20,000 epinephrine on the convex side of the most deviated part of the septum using $0^{\circ}$ rigid 4 $\mathrm{mm}$ endoscope. Hemitransfixation was made. Incision was not extended from dorsum to the floor as in classical incision but was extended both superiorly and inferiorly just as needed to expose the most deviated part.

A submucoperichondrial flap was raised using a suction elevator under direct visualization with a endoscope, underlying bone was exposed and the most deviated part was removed.The flap was repositioned back after suction clearance and edges of the incision were just made to lie closely without the need to suture. The nasal cavity was packed with merocele (Nasal pack), which is sponge like \& expands on getting wet and provides uniform pressure over all surfaces in contact. It also avoids mucosal abrasions while doing packing and removal of it.

The conventional approach involves headlight illumination and visualization with nasal speculum.

\section{Observation}

The demographic characteristics and clinical findings of Groups 1 and 2 are shown in Table 1. In total, 25Patient (16 men and 09women) were subjected to the endoscopic approach, and 25Patient(13 men and 12 women) were subjected to the convential approach. The mean age of the patients was $49.9 \pm 15.0$ years in Group 1 and $54.2 \pm 15.6$ years in Group 2 .

Most prevalent complaint in the patients of deviated nasal septum among study subjects was nasal obstruction (74\%) followed by anterior nasal discharge $(41 \%)$, headache (20\%), sneezing (15\%), post nasal drip $(8 \%)$, epiphora (7\%), hyposma (3\%), bleeding (3\%) and snoring $(3 \%)$.

All the patients were examined with thudicum's nasal speculum and with $0^{0}$ nasal endoscope. Deviated nasal septum was the most common finding and was present in all the 50 patients. Right sided septal deviation was present in 11 cases of conventional septoplasty group and 8 cases of endoscopic septoplasty group. Left sided deviation was present in 7 cases of both conventional and endoscopic septoplasty groups. Spur was present in 7 cases of conventional septoplasty group and 8 cases of endoscopic septoplasty group. Hypertrophied inferior turbinate was found in 11 cases of conventional septoplasty group and 11 cases of endoscopic septoplasty group. Discharge in the middle meatus was found in 3 cases of conventional septoplasty group and 1 case of endoscopic septoplasty group. Polypoid middle turbinate was seen in 1 case of endoscopic septoplasty group and concha bullosa was found in 1 case of endoscopic septoplasty group.

Anterior Rhinoscopy and Diagnostic Endoscopic Findings

\begin{tabular}{|l|c|c|c|c|}
\hline Findings & $\begin{array}{l}\text { Conventional } \\
\text { Septoplasty }\end{array}$ & $\begin{array}{l}\text { Endoscopic } \\
\text { Septoplasty }\end{array}$ & Total & Percentage (\%) \\
\hline Rt. DNS & 11 & 8 & 19 & 38 \\
\hline Lt. DNS & 7 & 9 & 16 & 32 \\
\hline Spur & 7 & 8 & 15 & 30 \\
\hline Hypertrophied I.T & 11 & 11 & 22 & 44 \\
\hline Polypoid M.T & 0 & 2 & 2 & 4 \\
\hline Concha Bullosa & 0 & 1 & 1 & 2 \\
\hline Discharge & 3 & 1 & 4 & 8 \\
\hline
\end{tabular}

The patients were divided into four groups based on nasal airflow as described by Gertner.

Group 1: severe nasal obstruction; group 2: moderate nasal obstruction; group 3: mild nasal obstruction; group 4: very mild nasal obstruction In conventional septoplasty group there were 5 patients belonging to group 1, 16 patients belonging to group 2, 3 patients belonging to group 3 and 1 patients belonging to group 4.In endoscopic septoplasty group there were 3 patients belonging to group 1, 15 patients belonging to group 2, 5 patients belonging to group 3 and 2 patients belonging to group 4 .

\begin{tabular}{|c|l|c|c|c|}
\hline Group & Nasal airflow $(\mathbf{c m})$ & $\begin{array}{l}\text { Conventional } \\
\text { septoplasty }\end{array}$ & $\begin{array}{l}\text { Endoscopic } \\
\text { septoplasty }\end{array}$ & Total \\
\hline 1 & $0-1$ & 5 & 3 & 8 \\
\hline 2 & $2-3$ & 16 & 15 & 31 \\
\hline 3 & $4-5$ & 3 & 5 & 8 \\
\hline 4 & $6-9$ & 1 & 2 & 3 \\
\hline Total & & 25 & 25 & 50 \\
\hline
\end{tabular}




\section{Postoperative Symptomatology}

Postoperative the were reviewed on 1,3 and 6 month . During each visit, patient were asked about benefit from the symptom. Out of 50 patients with nasal obstruction, 48 of the 50 patients were relieved of the symptom of which 23 of the 25 patients belonged to conventional and 24 of the 25 patients belonged to endoscopic septoplasty group. Nasal discharge did not persist in patients belonging to either of the groups. Headache persisted in 2 of the 10 patients in conventional septoplasty group. None of the patients in the endoscopic septoplasty group complained of headache. Hyposmia was relieved in patients belonging to endoscopic septoplasty group. Epistaxis was relived in patients belonging to conventional septoplasty group.

\section{Postoperative Finding}

All Patient undergo final examination at 6 month follow-up with 0 degree endoscope. Endoscopic septoplasty as far as objective and subjective evalution were concerned.

\begin{tabular}{|c|l|l|l|l|}
\hline Finding & $\begin{array}{l}\text { Conventialseptoplasty } \\
\text { Pre/postoperative }\end{array}$ & $\begin{array}{l}\text { Endoscopic Septoplasty } \\
\text { Pre/postoperative }\end{array}$ & Benifit & Percentage \\
\hline D.N.S & $25 / 0$ & $25 / 0$ & $50 / 50$ & 100 \\
\hline Nasal Discharge & $3 / 0$ & $1 / 0$ & $4 / 0$ & 100 \\
\hline $\begin{array}{l}\text { Hypertrophy } \\
\text { Turbinate }\end{array}$ & $2 / 11$ & $3 / 11$ & $22 / 17$ & 78 \\
\hline
\end{tabular}

\section{Complication}

The intraoperative and post operative complications were tabulated as follows.

\begin{tabular}{|l|r|r|r|}
\hline Complications & Conventional septoplasy & Endoscopic septoplasty & \multicolumn{1}{l|}{ Total } \\
\hline Haemorrhage & 8 & 1 & 9 \\
\hline Mucosal tear & 10 & 1 & 11 \\
\hline Synechae & 4 & 0 & 4 \\
\hline External deformities & 0 & 0 & 0 \\
\hline
\end{tabular}

In this study, 8 patients in conventional septoplasty group had intraoperative haemorrhage and only 1 patients in the endoscopic septoplasty group had this. Mucosal tear occurred in 10 patients belonging to conventional septoplasty group and 1 patients belonging to endoscopic septoplasty group. 4 patients belonging to conventional septoplasty had synechae formation in between septum and inferior turbinate. There was delayed healing at incision site in 3 patients belonging to endoscopic septoplasty group.

There were no external deformities in patients belonging to either of the groups.

\section{Discussion}

Olphen (2008) described that Cottle in 1963 gave the concept of conventional septoplasty which is done in 6 phases: (a) gaining acess to the septum; (b) correction of pathology; (c) removing pathology; (d) shaping removed cartilage and bone; (e) reconstruction of the septum; (f) stabilizing the septum.

Endoscopic septoplasty is not primarily meant for relieving nasal obstruction but mostly it is performed to gain access to surgical site as in cases of FESS but has distinct advantages- in peadiatric cases, in revision surgeries and cases with previous septal perforation and also in cases with isolated septal spurs.Complex deformities need correction by conventional approach so also the caudal deflections. Out of the 50 cases selected for endoscopic correction in the present study, endoscopic septoplasty alone was performed in 23 cases, 20 cases in conjunction with FESS and 7 cases in conjunction with DCR. Cantrell (1997)and Hwang et al. (1999) have reported similar incidence.Significantly higher rate of persistance of symptoms were found with conventional septoplasty as compared to endoscopic septoplasty in the present study and that of Nayak et al (2002)

In a study by Sindwani\& Wright (2003) 54\% patients with complaints of nasal obstruction and facial pain were cured and 38\% showed improvement and $8 \%$ were not benefited. Harley et al. (2003) observed significant improvement in patients with nasal obstruction and headache in endoscopic group as compared to conventional group. In the present study more number of patients were relieved from these symptoms in endoscopic septoplasty as compared to conventional group. This is in aggrement with the observations of Gulati et al. (2009).

Park et al. (1998) observed that the synechiae were formed in significantly less number in patients of endoscopic septoplasty group as compared toconventional group; similar results were found in the present study. Complication rate in endoscopic septoplasty group was $3 \%$, in the present study while complication rate was found to be $2.08 \%$ and $5 \%$ by Gupta et al. (2005) and Hwang et al. (1999) respectively. 
The traditional approach to septoplasty involves headlight illumination, visualization through a nasal speculum, and surgical instruments that are typically disparate from that used during standard endoscopic procedures. These circumstances can be suboptimal when treating a narrow nose, approaching posterior deviation, or required frequent exchanges between headlight and endoscope. In addition impaired visualization may predispose to nasal mucosal trauma, which can compromise endoscopic visualization during sinus surgery.

\section{Conclusion}

Evolution of endoscope septoplasty has revolutionized the history of septal surgery. Posterior deviation, high deviation and spurs can be dealt in a better way with this technique. Illumination is better with endoscopes, and so it helps in proper planning of the surgery. In ourstudy, the assessment showed endoscopic septoplastytobe a better option for septal surgery. Under endoscopic guidance, the bleeding pointscanbe easily visualized and hemorrhage can be reduced.Mucosal tears can be avoided as the vision is better inendoscopic technique unlike conventional septoplasty. Soendoscopicseptoplasty appears to be a better alternativeto conventional septoplasty.

\section{Reference}

[1]. Chow JM. Evaluation of rhinologic headache. In: Advanced endoscopic sinus surgery. Stankiewicz JA Eds.; $2^{\text {nd }}$ Edn.; Mosby St.Louise, 1995; pp. 121-126.

[2]. Dinis PB, Haider H: Septoplasty- Long term evaluation of results. American Journal of Otolaryngology, 2002; 23(2):85-90.

[3]. Gaskin RE: A Surgical Staging System for chronic sinusitis. American Journal of Rhinology, 1992;6(1) 5-12.

[4]. Giles WC, Gross CW, Abram AC, Greene WM, Avner TG: How I do it Head \& Neck \& Plastic surgery a tangeted problem an d its solubier. Endoscopic septoplasty. The Laryngoscope, 1994; 104(12): 1507-1509.

[5]. Gulati S P, Wadhera R, Ahuja N, Garg A, Ghai A: Comparative evaluation of endoscopic with conventional septoplasty. Indian Journal ofOtolaryngol and Head Neck Surgery, 2009; 61(1): 27-29.

[6]. Gupta M, Motwani G: Comparative study of endoscopic aided septoplasty and traditional septoplasty in posterior nasal septal deviations. IndianJournal of Otolaryngology \& Head and Neck Surgery, 2005; 57(4):309-311.

[7]. Gupta N. Endoscopic septoplasty. Indian Journal ofOtolaryngology and Head \& Neck Surgery ,2005;57(3):240-243.

[8]. Harley DH, Powitzky ES, Duncavage J. Clinical outcomes for the surgical treatment of sinonasal headache. Otolaryngology Head \& Neck Surgery, 2003; 129(3): 217-221.

[9]. Hwang PH. Mc Laughlin RB, Lanza DC, KennedyDWl: Endoscopic Septoplasty: Indications, technique and results. Otolaryngology Head \& Neck Surgery, 1999;120(5): 678-682.

[10]. Lanza DC, Kennedy DW, Zinreich SJ: Nasal endoscopic and its Surgical applications. In : Lee KJ. Essential Otolaryngology: head and neck surgery. $5^{\text {th }}$ Edn.; Appleton \& Lange, 1991; pp. 373-387.

[11]. Lanza DC, Rosin DF, Kennedy DW: Endoscopic septal spur resection. American Journal of Rhinology, 1993; 7(5): 213-216.

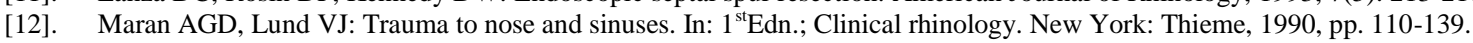

[13]. Nayak D R, Balakrishnan R, Murthy KD: An endoscopic approach to the deviated nasal septum- a preliminary study. The Journal of laryngology \& Otology,

[14]. 1998;112(10):934-939.

[15]. Nayak D R, Balakrishnan R, Murthy KD, Hazarika P: Endoscopic Septoturbinoplasty: Our update series. Indian Journal of Otolaryngology and Head \& Neck Surgery, 2002;54(1):20-24.

[16]. Olphen AFV: Septum. In: Scott Brown's Otorhinolaryngology, Head and Neck Surgery, Vol. 2, Gleesan M, Browning GG, Burtan

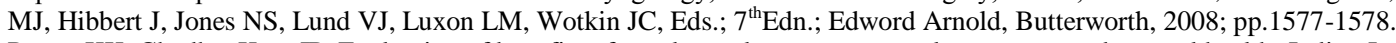

[17]. Pannu KK, Chadha, Kaur IP. Evaluation of benefits of nasal septal surgery on nasal symptoms and general health. Indian Journal of Otolaryngology \& Head andNeck Surgery, 2009; 61(1):59-65.

[18]. Park DH, Kim TM, Han DG, Ahn KY. Endoscopic assisted correction of the deviated nose. AestheticPlastic Surgery, 1998; 22(3): 190-195.

[19]. Rao JJ, Kumar ECV, Babu KR, Chowdary VS, Singh J, Rangamani SV: Classification of nasal septal deviation-relation to sinonasal pathology. Indian Journal ofOtolaryngology\& Head and Neck Surgery, 2005; 57(3):199-201.

[20]. Sautter NB, Smith TL: Endoscopic Septoplasty. Otolaryngologic Clinics of North America, 2009;42(2):253-260.

[21]. Sindwani R, Wright ED: Role of endoscopic septoplasty in the treatment of atypical facial pain. Journal ofOtolaryngology, 2003; 32(2): 77-80.

[22]. Toffel PH: Septoplasty: It's place in modern management of chronic nasal and sinus obstructive disease. In: Rhinologic and sinus

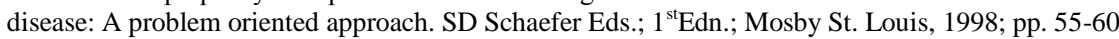

[23]. Yanagisawa E, Joe J: Endoscopic septoplasty. Ear NoseThroat Journal, 1997; 76(9):622-623. 